\title{
LAS CUSTODIAS DE HERNANDO ORTIZ, UN PLATERO DESCONOCIDO DE LA GRANADA DE PRINCIPIOS DEL SIGLO XVII
}

José Antonio Peinado Guzmán

Universidad de Granada

Data recepción: 2017/12/25

Data aceptación: 2018/04/16

Contacto autor: pepeinado@hotmail.com

ORCID: https://orcid.org/0000-0003-2085-441X

\section{RESUMEN}

El presente artículo pretende dar a conocer la figura de un orfebre granadino, Hernando Ortiz, que trabajó en los últimos años del siglo XVI y los primeros del siglo XVII. Este personaje, hasta ahora desconocido, parece ser, que trabajó de manera oficial para el arzobispado de Granada, por la cantidad de piezas contratadas en los legajos de Contaduría Mayor consultados. Aunque en este trabajo nos centramos en las custodias que realizó, dejamos constancia de los numerosos utensilios litúrgicos que hizo, la mayoría de los cuales han desaparecido con el paso del tiempo.

Palabras clave: Hernando Ortiz, siglos XVI-XVII, orfebrería, custodias, Granada

\section{ABSTRACT}

This article takes as its subject the Granadan goldsmith Hernando Ortiz, who was active in the late 16 th and early 17 th centuries. Hitherto unknown, Ortiz appeared to have worked on an official basis for the archbishopric of Granada, judging by the amount of pieces he was commissioned to create and which are recorded in the Contaduría Mayor (accounts) consulted. Although our focus in this study are the monstrances he made, we also make note of the many liturgical items he fashioned, most of which have disappeared over time.

Keywords: Hernando Ortiz, 16th and 17th centuries, goldsmithing, monstrances, Granada

\section{Introducción}

Afrontar el tema de la platería en Granada supone valorar y tener en cuenta los clásicos tratados de la orfebrería granadina, tanto de Manuel Capel Margarito', como de Pilar Bertos Herrera². Si bien el primero de ellos, más básico, realiza una catalogación de piezas de los templos más señeros de la provincia de Granada, los estudios de la profesora Bertos, combinan el trabajo de campo con la investigación de algunos archivos parroquiales.

El origen de la orfebrería granadina, sin olvidar la consabida tradición árabe, surgirá tras la con- quista de la ciudad en 1492. Así pues, las primeras referencias documentales al respecto datan de las Ordenanzas que los muy llustres, y magnificos Señores de Granada mandaron guardar para la buena governacion de su Republica en 1531². A lo largo de todo el siglo XVI se irá fraguando el gremio de plateros en la ciudad juntamente con la Hermandad de San Eloy, la propia de los orfebres, referida también en el mencionado documento de ordenanzas. Sólo en la centuria del Quinientos se contabilizaban fehacientemente más de un centenar de maestros plateros, dato que muestra la pujanza del oficio en 


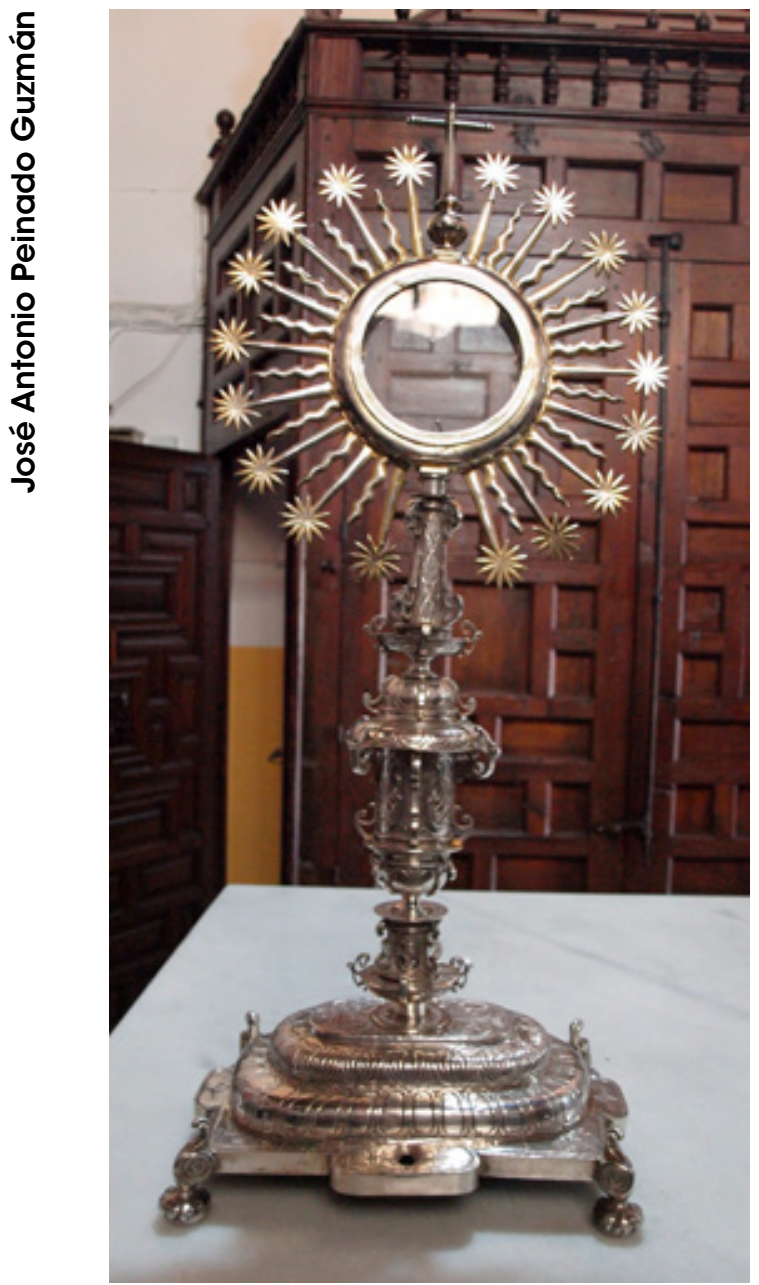

Fig. 1. Custodia. Iglesia parroquial de Albolote (Granada). Hernando Ortiz. 1602

estas fechas ${ }^{4}$. Curiosamente, en el siguiente siglo, la cifra merma considerablemente. Probablemente se conjuguen dos factores para explicar este hecho: la falta de datos, por un lado, y la enorme necesidad que requerían las parroquias de objetos sagrados para el culto en el siglo XVI, algo que, posteriormente, ya no era preciso. Con seguridad, al menguar la demanda, disminuyó también el trabajo y el personal dedicado a la platería en Granada.

Es en este contexto, a caballo entre los dos siglos, cuando aparece la enigmática figura del orfebre Hernando Ortiz. Y es que poco sabemos de él a nivel biográfico. En primer lugar, desco- nocemos su marca de platero, por ejemplo. Ninguna de las piezas que aportamos la poseen. Las primeras obras documentadas que se han hallado datan de 1600, siendo la última de $1617^{5}$. Aun así, con respecto a la marca del orfebre, tal y como atestigua la profesora Sanz Serrano, no siempre aparece en las obras. En ocasiones, se han borrado, han desaparecido por restauraciones $\mathrm{o}$, sencillamente nunca las tuvieron, como ocurre frecuentemente en las piezas de la primera mitad del siglo XVII. . Cabe la posibilidad que, como se ha podido comprobar en los libros de contaduría, al tratarse del platero que trabajó oficialmente para el arzobispado -puesto que ningún otro nombre aparece en dichos documentos-, sus obras fuesen realizadas en serie, a modo de obrador, y que por esa razón tampoco fuese necesaria la aparición de su marca. El único dato biográfico que hemos hallado es que era vecino de la collación de San Matías, tal y como se refleja en el contrato notarial de una cruz parroquial para el templo de San Andrés?

El proceso de indagación y la metodología empleada para acercarnos a este personaje ha sido la combinación de la investigación archivística con el trabajo de campo. De modo casual se encontraron reiteradas referencias de abundantes obras de este orfebre en la serie de Contaduría Mayor del Archivo Histórico Diocesano de Granada. Una vez contrastado con lo que hay publicado sobre platería y plateros granadinos, se comprobó que la figura de Hernando Ortiz no había sido trabajadå. Extractada la información del citado archivo, se recurrió al Archivo Municipal de Granada para averiguar datos biográficos. Se consultaron los diversos Expedientes de Gremios tomando como referencia un amplio arco temporal para asegurarse abarcar su vida; se revisó el Cuaderno de registro de títulos de oficios que da comienzo en 1550 por si aparecía algún dato; se buscó en los padrones o libros de avecindamiento, así como en legajos concernientes al pago de impuestos por si se hallaba alguna información al respecto. Finalmente, como último recurso, se revisó la Ejecutoria en favor de Agustín de Nicuesa, un platero coetáneo por si aparecía algo acerca de Hernando Ortiz. Toda la búsqueda fue baldía. Por el contrario, tanto en el Archivo del Sacro Monte como en el Archivo de la Catedral de Granada sí se encontraron referencias de algunas de sus 
piezas. Documentadas las obras, se procedió a su búsqueda en un arduo trabajo de campo. Parte de esa labor se ofrece en este artículo, mas centrándose en las custodias del tipo ostensorio que realizó, unas conservadas y otras, aunque desaparecidas con el paso del tiempo, se da fe de que existieron.

\section{Custodias relacionadas con el platero Hernando Ortiz}

La primera referencia que se ha hallado es una custodia (ostensorio) realizada para la iglesia parroquial de Albolote (Granada) en 1602 (fig. 1). La misma fue encargada el 18 de mayo del citado año por el beneficiado de dicha iglesia Andrés López y realizada por el platero Hernando Ortiz. Como curiosidad, en el margen izquierdo del legajo aparece citado el platero Luis de Veas, aunque realmente, en el interior del documento, ya no se nombra, siendo únicamente mencionado el susodicho Ortiz. El peso del ostensorio ascendió a "once marcos y cuatro onzas y media", costando mil cuatrocientos veintiocho reales. Cuatrocientos de ellos fueron costeados gracias a los corridos de un censo atrasado de doña María Xarava. Ha de comentarse, asimismo, que, aunque en el contrato se establecía que la custodia debía estar acabada un mes después de su concertación, lo cierto es que se demoró el trabajo varios meses, puesto que la entrega de la misma se efectuó el 21 de febrero de 1603․ En la obra de Pilar Bertos Herrera se cita la existencia en ese templo de una custodia anónima de la primera mitad del siglo XVII, que consideramos que podría corresponder con la hallada en la documentación que ofrecemos ${ }^{10}$. No aparece marca de platero, pero el estilo manierista que se observa permite elucubrar que se trate de la misma.

La pieza constituiría uno de los modelos más elaborados que Hernando Ortiz ejecuta. En la misma, realizada en plata, se puede contemplar que su base es rectangular, apoyada sobre cuatro garras sobre bolas, y en la que se inscribe un óvalo. Sobre esa estructura, se levantan dos cuerpos escalonados y ovalados en tamaño decreciente. En la decoración incisa del primero de ellos se observan espejos, mientras que en la del segundo abundan los motivos vegetales agallonados. Destacan, asimismo, otros detalles de tipo floral y geométrico en la superficie. En el astil, de forma abalaustrada,

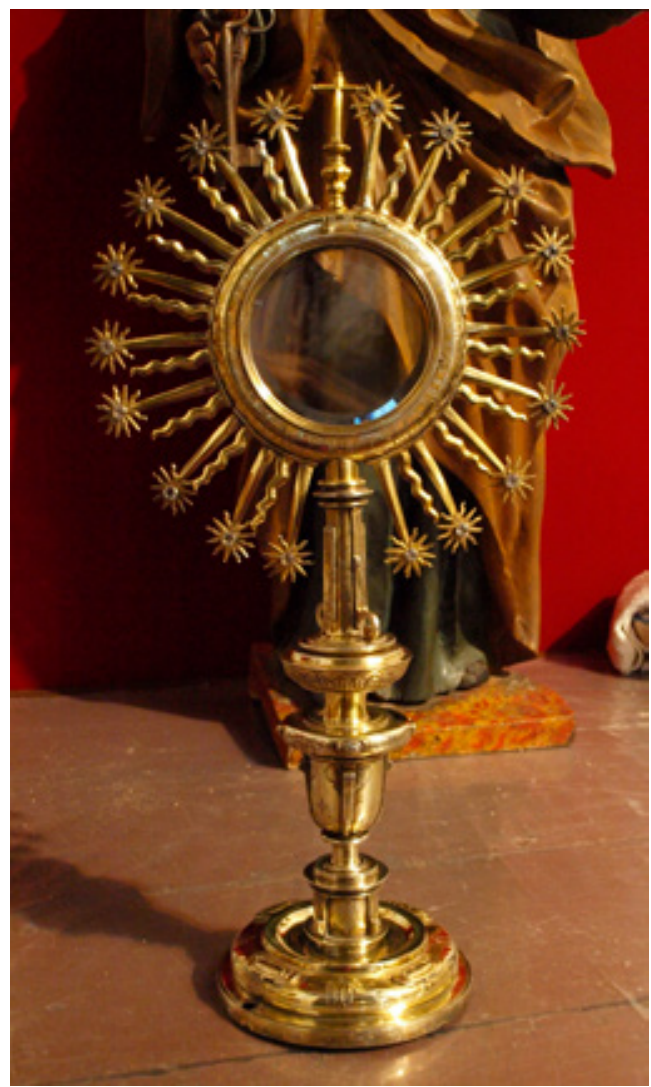

Fig. 2. Custodia. Iglesia parroquial de San Pedro y San Pablo (Granada). Hernando Ortiz. 1603

destacan tres partes principales. Sobre un pequeño estrangulamiento se alza el primer nivel, compuesto por un plato moldurado. En el nudo se observa su forma ovoide, sobre el que se levanta el vástago o cuello, que se estrecha progresivamente, y que antecede al sol. Todo el astil está decorado con ces, asas, costillas, gallones y decoración vegetal. El citado sol ofrece tanto rayos rectos como curvos, que se van alternando. Los primeros, terminados en estrellas de once puntas, suman la cantidad de dieciocho. Los ondulados, de menor tamaño, conforman dieciséis resplandores. Corona la custodia una cruz latina, con los brazos terminados en bolas, ubicada sobre peana abalaustrada. La pieza posee una altura de $77 \mathrm{~cm}$. y una base de $34 \mathrm{~cm}$.

La siguiente custodia, siguiendo el criterio cronológico, sería la que hiciera para la parroquial capitalina de San Pedro y San Pablo"1 (fig. 2). La 


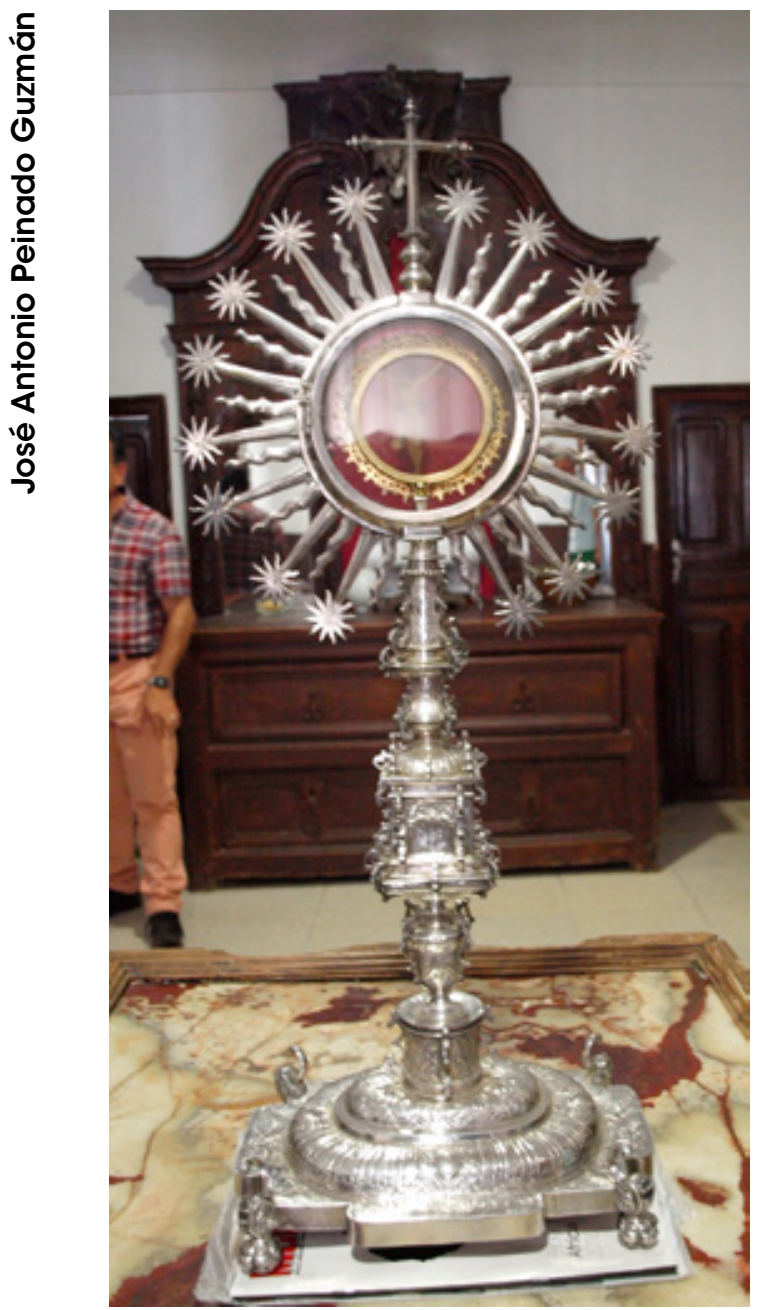

Fig. 3. Custodia. Iglesia parroquial de Quéntar (Granada). Hernando Ortiz. 1608

misma se terminó de pagar el 19 de marzo de 1603, ascendiendo su coste a mil seiscientos treinta y ocho reales, habiendo sido concertada su hechura por el beneficiado Cristóbal de Montalbo.

El modelo de custodia que nos ofrece la de la parroquial de San Pedro y San Pablo se corresponde al del clásico ostensorio'12, como todos los que se exponen en este artículo, siendo realizado en plata sobredorada, y caracterizado por una pequeña base circular, en tres niveles, donde el intermedio es más ancho que los restantes. En él se dispone una decoración basada en espejos ovales, cuatro en total, intercalados por motivos geométricos ovalados y triangulares. Sobre esa base arranca el astil, donde se pueden observar varios cuerpos. En el primero de ellos, cilíndrico, combina minúsculas asas con motivos vegetales entre los citados salientes. Sobre éste, se contempla el estrangulamiento del astil, también cilíndrico. Se eleva sobre el mismo el nudo del ostensorio que presenta, asimismo, dos partes diferenciadas: la primera, con forma ovoide emulando la forma de un jarrón o el cáliz de una flor; y la segunda, situada sobre el pequeño cuerpo cilíndrico que separa ambas, de aspecto circular. Todo el nudo se presenta decorado con motivos geométricos y vegetales en sus molduras. Especialmente resalta la ubicada coronando la parte ovoide, por su combinación de la citada decoración con elementos en relieve a modo de minúsculos espejos. Sobre el nudo, el astil se completa con un nuevo cuerpo cilíndrico, el cuello, en el que se vislumbran decoraciones geométricas rectangulares verticales, así como dos salientes en forma de ces investidas. Este cuerpo vendría a soportar el sol, compuesto por rayos rectos y curvos. Los resplandores rectos, dieciocho en total, terminan en estrellas de once puntas con pedrería. Los curvos suman un total de dieciséis. Corona el sol una cruz latina con sus brazos terminados en bolas, situada sobre un elemento con forma abalaustrada. La custodia, finalmente, tiene una altura de $64 \mathrm{~cm}$. y un pie de $18,5 \mathrm{~cm}$. La misma, citada en la obra de Capel Margarito como anónima granadina del primer tercio del siglo XVII, es también mencionada por Pilar Bertos como de la primera mitad de dicha centuria ${ }^{13}$. Esta pieza consideramos, a la luz de los documentos encontrados, que se trata de la realizada por Hernando Ortiz para la parroquia en 1603.

Interesante resulta el ostensorio de la parroquial de Quéntar (Granada) (fig. 3). Según la documentación encontrada, le fue encargado a Hernando Ortiz uno en $1608^{14}$. Barajamos la hipótesis de que pueda ser el que exponemos a continuación, y que la profesora Bertos cita como una pieza anónima de la primera mitad del siglo $X V \|^{15}$. Encargado por el mayordomo don Gaspar de Pernía, se pagó por el mismo doscientos trece reales. El peso del contraste ascendió a "dos marcos y dos onças y seis ochavas". 
El modelo es algo más elaborado que los precedentes, denotando formas más manieristas. La base de la pieza, nuevamente, es rectangular, inscribiéndose un óvalo en la misma y recortándose en las esquinas con formas redondeadas. La misma se apoya en las acostumbradas garras sobre bolas. Estructurada en graderío, se distinguen dos pisos ovalados, separados entre sí por uno de menor tamaño a modo de bisel. Todo ello se presenta decorado con motivos vegetales incisos y gallones. Son reseñables en el primer piso cuatro destacados medallones ornamentados con minúsculas espigas. De la base se alza el astil, de hechuras abalaustradas, en el que se observan cuatro partes diferenciadas. La contigua a la base es de aspecto cilíndrico, con decoración vegetal incisa y con elementos en tornapuntas. Sobre ésta se dispone el estrangulamiento que estrecha el astil seguido de una forma ovoide, a modo de bellota, que reitera los motivos decorativos incisos, a los que se añaden asas. La manzana se estructura a modo de templete, en el que se aprecian arcos de medio punto con sus respectivas impostas, y llegándose a observar detalles tan minúsculos como columnas de estilo dórico en las cuatro portadas, veneras en la hornacina y hasta las albanegas de los citados arcos. El templo se cubre con pequeña cúpula semiesférica gallonada y minúsculos pináculos en las esquinas. Completa la decoración los elementos en tornapuntas característicos del modelo. Se une al sol mediante el cuello, elemento cónico que se va estrechando progresivamente y que queda cortado casi en la mitad por una semiesfera truncada. Todo perpetúa el tipo de decoración ya mencionada. El sol repite el modelo ya referido de alternancia de rayos rectos terminados en estrellas con rayos curvos de menor longitud. La diferencia es que los primeros suman la cantidad de dieciséis, mientras los segundos conforman catorce. Igualmente, se reitera idéntico remate en cruz a los modelos ya descritos. La custodia mide $74 \mathrm{~cm}$. de altura con una base de $32 \mathrm{~cm}$.

Analizando la documentación consultada, meses después del encargo del ostensorio de Quéntar, se realiza el de la localidad de íllora (Granada) ${ }^{16}$ (fig. 4). Pensamos que el mismo se corresponde con el que Bertos recoge como pieza anónima de la primera mitad del siglo XVII17. De inferiores dimensiones, está realizado en plata sobredora-

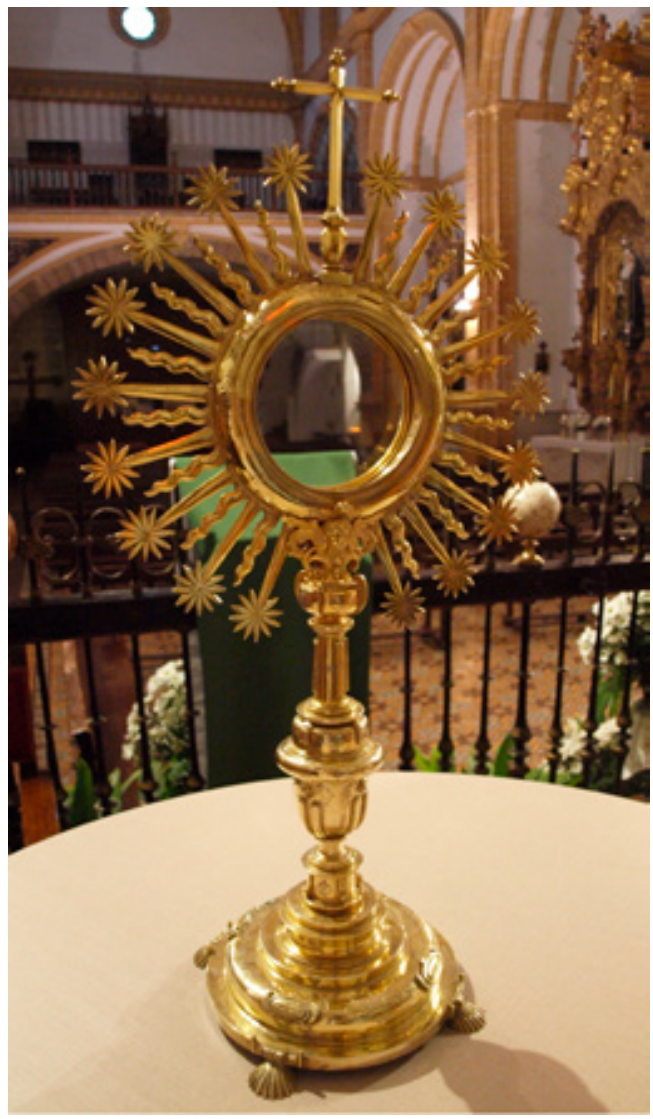

Fig. 4. Custodia. Iglesia parroquial de Íllora (Granada). Hernando Ortiz. 1608

da. Consta de una base circular en graderío, en la que se aprecian tres pisos de menor tamaño y biselados, juntamente con uno central más grande ovalado. Todo ello se apoya en cuatro patas con forma de conchas hacia abajo. Presenta decoración geométrica incisa, así como unos óvalos horizontales en relieve que embellecen la pieza. En el astil se distinguen tres partes diferenciadas. La más cercana a la base es cilíndrica, con decoración punteada incisa y geométrica, destacando, asimismo, los correspondientes salientes apuntados. La manzana es de forma ovoide y se presenta decorada con gallones y puntas de diamante. El astil se va estrechando hasta unirse al sol. El mismo tiene una base circular con decoración incisa punteada y ces, sobre la que se observan dos rostros de ángeles alados, uno a cada lado. El sol repite las formas descritas previamente en otros ejemplos (dieciocho 


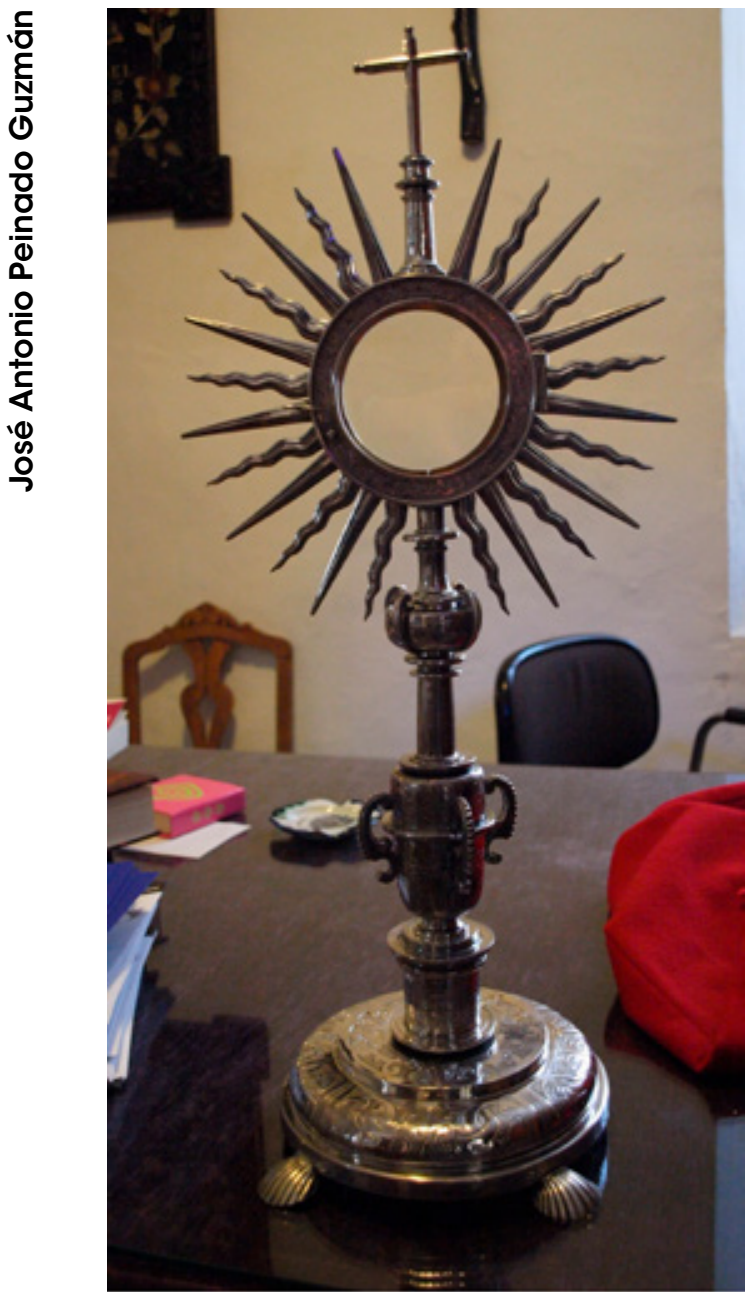

Fig. 5. Custodia. Iglesia parroquial de Güevéjar (Granada). Hernando Ortiz. 1609

rayos con puntas de estrellas y dieciséis con rayos ondulados). El ostensorio mide $68 \mathrm{~cm}$. de altura y $18 \mathrm{~cm}$. de diámetro.

Siguiendo la línea cronológica, el siguiente ostensorio encontrado sería el de la localidad de Güevéjar (Granada) (fig. 5). Dicha pieza evoca las formas de la realizada en íllora. Realizada en plata, presenta una base circular apoyada sobre conchas. Estructurada en tres niveles, ofrece una decoración a base de motivos vegetales. En el astil se observan, asimismo, las clásicas tres partes: el gollete cilíndrico más cercano a la base; el nudo, con forma ovoide y engalanada con costillas; y finalmente el cuello, con similar elemento circular decorado con pequeñas costillas en mitad del vástago. El sol reitera los rayos rectos con los curvos (doce de cada tipo), rematándose con una cruz de similares características a las ya descritas previamente. No se observan en este caso puntas de estrellas en los rayos. Cabe reseñarse la decoración en el viril, a base de motivos geométricos compuestos por ces enroscadas encadenadas de forma incisa. Mide 54 $\mathrm{cm}$. de altura y $16 \mathrm{~cm}$. de diámetro.

Según la profesora Bertos Herrera, el ostensorio constituiría una obra anónima de finales del siglo $\mathrm{XVI}$ o principios del XVIII'. La documentación analizada nos permite elucubrar la posibilidad de que la pieza fuese la encargada a nuestro platero Hernando Ortiz, y que sería recibida por el beneficiado de la parroquial Fernando de Rivera el 21 de mayo de $1609^{19}$. La custodia pesó ocho marcos, dos onzas y seis ochavas, ascendiendo su coste a 810 reales, de los cuales, 40 ducados (440 reales), fueron donados por el licenciado Montenegro, beneficiado del dicho lugar y vicario de la ciudad de Loja, por testamento. Aquella donación parece ser que no era suficiente para la factura del ostensorio, como consta en la nota enviada a la Contaduría Mayor del Arzobispado por el beneficiado Fernando de Rivera, quien afirma que con esos cuarenta ducados sólo habría para la plata. Por ello solicita que al arzobispo que "se sirva que las yglesias den la hechura de la dicha custodia". Como curiosidad, la pieza presentaba dos campanillas en su origen que, con el tiempo, han desaparecido.

Ya en 1610 encontraríamos la custodia de Monachil (fig. 6). De similares trazas al ostensorio de Albolote, esta pieza viene recogida por la profesora Bertos Herrera como una obra anónima de la primera mitad del siglo XVII²0. Según la documentación encontrada, y atendiendo al criterio estilístico, consideramos que podría tratarse de la custodia que fue encargada al platero Hernando Ortiz y que fue entregada al beneficiado de Huétor, el maestro Francisco de Paniza Ladrón, el día 9 de agosto de 1610. La pieza costó 189 reales, pesando dos marcos, una onza y ochava y media ${ }^{21}$.

En esos mismos rasgos estilísticos se mantiene la custodia de Padul (fig. 7), estableciéndose un paralelismo casi mimético con el ostensorio de la localidad de Albolote. La pieza viene recogida por Bertos Herrera en su catálogo22, aunque el hecho 


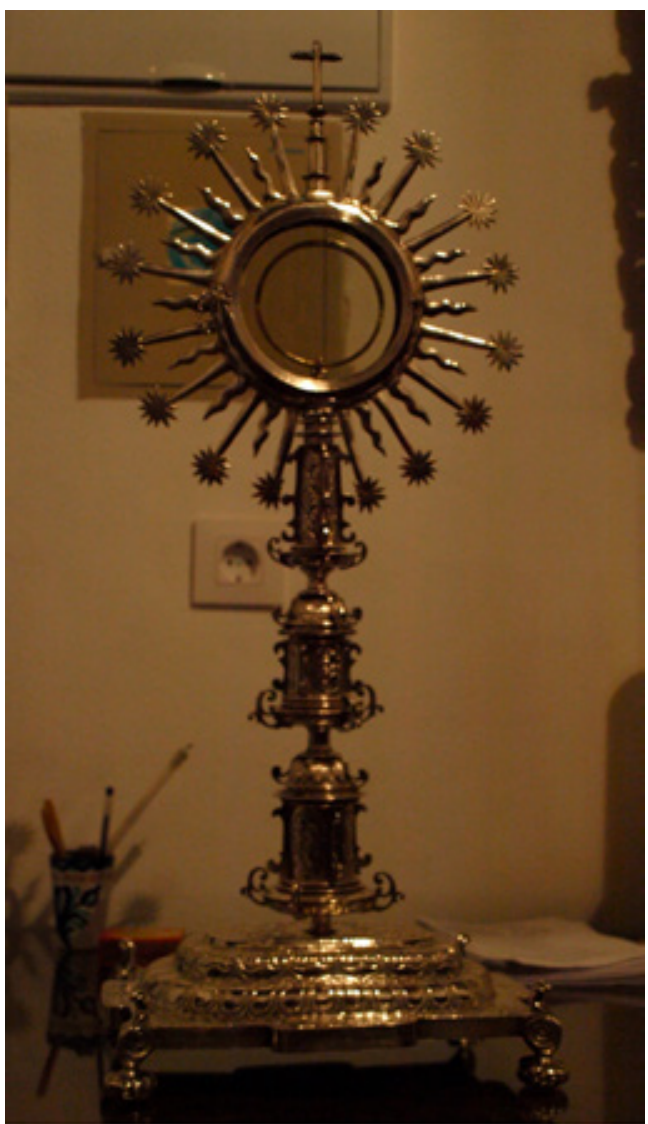

Fig. 6. Custodia. Iglesia parroquial de Monachil (Granada). Hernando Ortiz. 1610

de haber sido restaurada en 1743 , haya podido inducir a pensar erróneamente que la obra se trataba del platero Gallego, cuando realmente se observa que es una custodia manierista y no de corte barroco pleno. Independientemente de la intervención, comparándola con las que se han citado previamente, y contrastando todo ello con la documentación encontrada, podemos postular que podría tratarse de la custodia que se le encargó para la localidad a Hernando Ortiz en 161623. La misma pesó seis marcos, seis onzas y tres ochavas, ascendiendo su coste a 663 reales. El ostensorio sería recibido el 30 de julio de 1616 en la parroquial por el doctor Basilio Altamirano.

Dentro de las posibles custodias atribuibles a su obra se encontraría la del municipio de Huétor Vega (fig. 8). Si bien hemos encontrado docu-

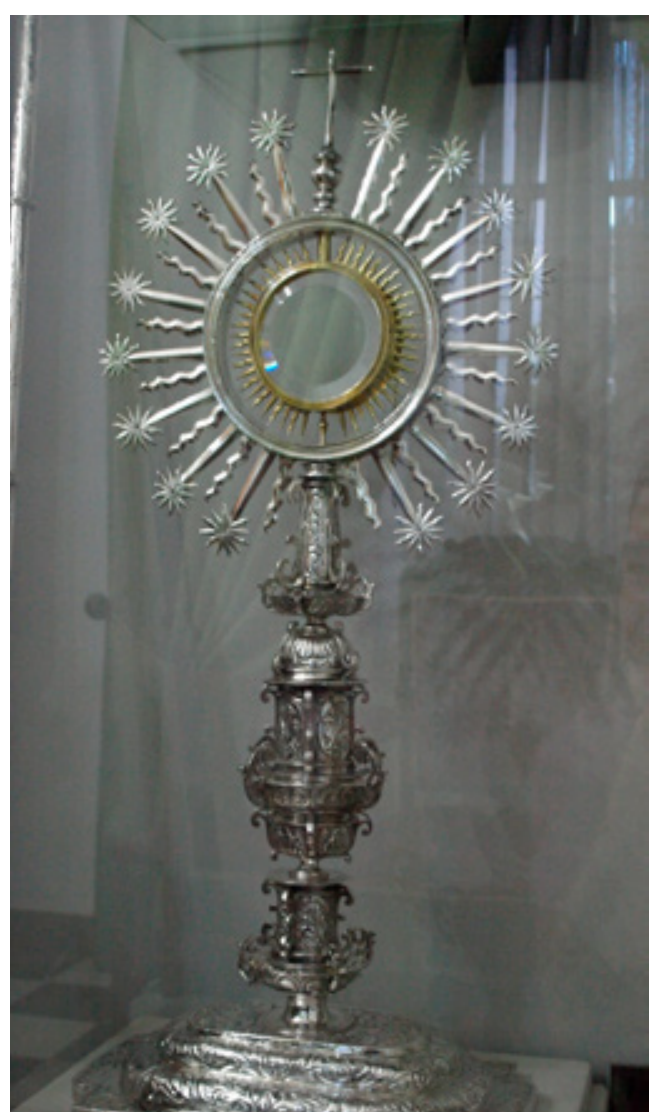

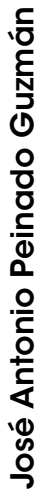

Fig. 7. Custodia. Iglesia parroquial de Padul (Granada). Hernando Ortiz. 1616

mentalmente la referencia de que Hernando Ortiz hizo una para esa localidad en $1615^{24}$, lo cierto es que cuando la hemos analizado visualmente, el astil se observa más posterior en el tiempo, como un elemento más barroco. Cabe la posibilidad de que originariamente el ostensorio sea de las fechas de las que hablamos, pero que haya sufrido una intervención barroca posterior (tanto en la base como en el astil). Denota esta opción el hecho de que el nudo del astil está invertido, como si lo hubiesen colocado al revés, algo que no es lógico. En cambio, el sol sí mantiene los estilemas propios de la obra de Hernando Ortiz. No deja de ser una hipótesis que lanzamos, ateniéndonos a la documentación hallada.

Finalmente, completaríamos la obra de este platero en materia de custodias, añadiendo otras que, 


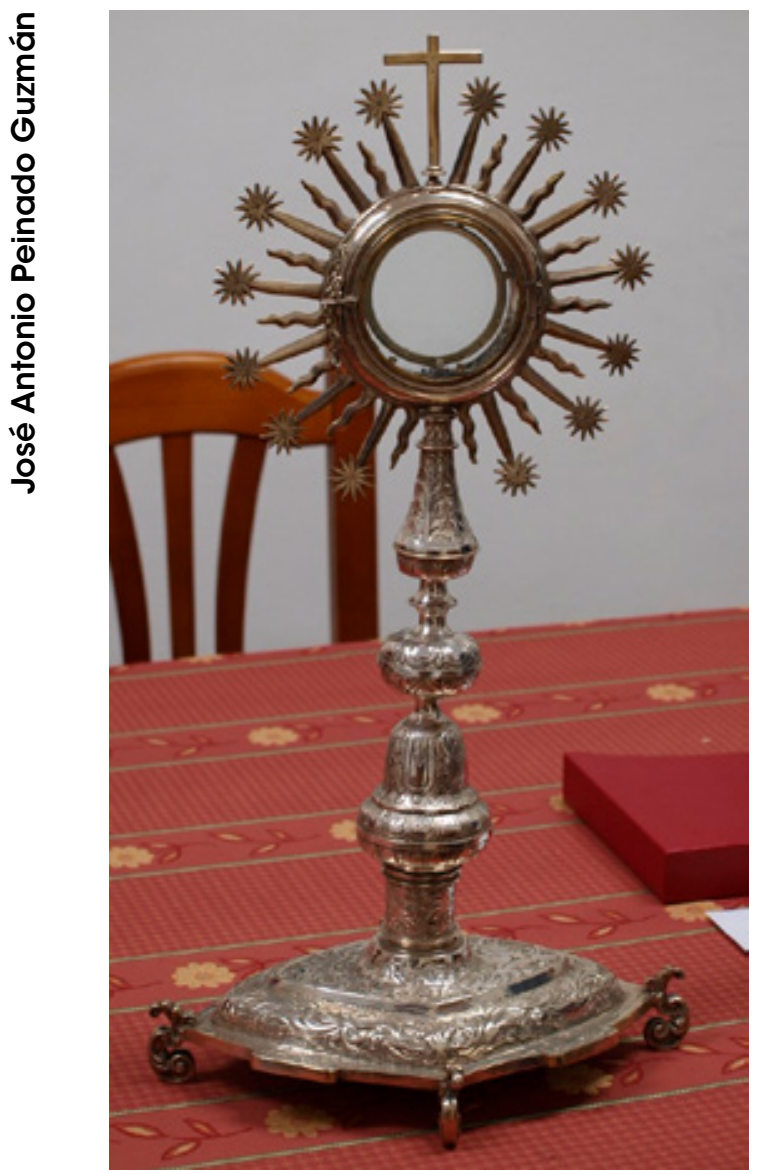

Fig. 8. Custodia. Iglesia parroquial de Huétor Vega (Granada). Atrib. Hernando Ortiz. 1615

habiendo encontrado su documentación, el paso del tiempo ha impedido que lleguen hasta nosotros. En este sentido podríamos destacar el caso de una custodia para Moclín (Granada) en 160425, otra para Güevéjar (Granada) en 160926, otra para la iglesia capitalina de Santa Escolástica en 1612²7, otra para la localidad de Guadahortuna (Granada) en $1612^{28}$, otra para Churriana de la Vega en $1614^{29}$, otra para Albuñuelas (Granada) en 161530, otra para Dalías (Almería) en 1616 ${ }^{31}$, haciendo en el mismo año sendas para los municipios granadinos de Cogollos Vega ${ }^{32}$ e Iznalloz ${ }^{33}$. Destacar, asimismo, un pie de plata para una custodia de Huétor Santillán (Granada) ${ }^{34}$. Dejamos para el final dos casos concretos. Nos referimos a sendas piezas, una en la Basílica de la Virgen de las Angustias ${ }^{35}$, en la capital, de
1610 y otra en la parroquial de la localidad de Las Gabias de $1608^{36}$. Aunque tenemos la documentación archivística, no se nos ha permitido acceder a las mencionadas custodias para su fotografiado, debido a la negativa de los sacerdotes.

\section{Conclusiones}

Como conclusión a todo lo que hemos expuesto, podríamos decir que el trabajo realizado es una labor de hipótesis razonada. Hallados unos documentos y encontradas unas piezas en los respectivos lugares que los textos mencionan, simplemente se han relacionado los datos con las custodias. Aun así, hemos de ser conscientes que cabe la posibilidad del error, por eso utilizamos el término "hipótesis razonada". Al no existir marca de platero ni algún tipo de punzón que avale con más certeza las autorías, siempre queda la posibilidad de la duda. Igualmente, la fragilidad de este tipo de elementos orfebres, hace que con el tiempo puedan haber desaparecido por el uso de los mismos, siendo sustituidos por otros de semejantes características y de hechura más o menos coetánea en el tiempo. Por otro lado, refuerza nuestra idea el hecho de que las custodias que exponemos mantengan cierto estilo manierista, amén de un parecido más que notable en su elaboración entre varias de ellas. Por tanto, creemos plausible la posibilidad de que las piezas que hemos mostrado fuesen realizadas por el orfebre Hernando Ortiz a principios del siglo XVII.

Asimismo, mediante este artículo pretendemos dar a conocer la figura de este platero, hasta ahora completamente desconocido en Granada, y que vivió y trabajó a caballo entre el siglo XVI y XVII. Aun así, la muestra que ofrecemos, únicamente centrada en sus custodias (hemos dejado al margen cruces, cálices, crismeras...), nos aporta un leve acercamiento a su obra. No olvidemos, como comentábamos en la nota a pie de página 5 que, debido al incendio del Archivo Histórico Diocesano, la serie de Contaduría Mayor no se ha conservado completa, por lo que, especialmente en los extremos de fechas, nos falta una relación entera de su trabajo. Esperamos, finalmente, que el dar a conocer a este personaje sirva para que, en futuras investigaciones y publicaciones, se pueda profundizar más en su vida y su obra. 
NOTAS

1 M. Capel Margarito, Orfebrería religiosa de granada, Granada, 1986.

2 P. Bertos Herrera, El tema de la Eucaristía en el arte de Granada y su provincia, Universidad de Granada, Granada, 1985; P. Bertos Herrera, Los escultores de la plata y el oro, Universidad de Granada, Granada, 1991

3 P. Bertos Herrera, El tema de la Eucaristía... (vol. I), op. cit., pp. 265266.

${ }^{4}$ P. Bertos Herrera, Los escultores..., op. cit., pp. 159-178.

${ }^{5}$ En este sentido cabe aclarar cierta inexactitud con respecto a las fechas aportadas. El gran montante de sus obras ha sido extraído de los legajos de Contaduría Mayor del Archivo Histórico Diocesano de Granada. Mas la serie no está completa. Debido al incendio que se produjo en el mismo en 1981 se perdieron algunos fondos. Concretamente, de 1584 se salta a 1600 . Faltan también los documentos de 1617 y 1618, no habiéndose hallado más piezas de este platero a partir de 1619. A la hora de acotar su obra, resulta muy difícil conocer qué realizó antes de 1600, de igual modo que tampoco sabemos mucho de los dos años referidos del XVII, aunque sí se ha llegado a documentar una pieza en la abadía del Sacro Monte de 1617.

${ }^{6} \mathrm{M}^{\mathrm{a}} \mathrm{J}$. Sanz Serrano, La orfebrería sevillana del Barroco (2 vols.), Diputación de Sevilla, Sevilla, 1976, p. 119

7 Archivo Histórico Diocesano de Granada [AHDGr.], Legajo 332-F, pieza 2, Contaduría Mayor, pliego de San Andrés, año 1605, s/f. Habiendo consultado los fondos del archivo parroquial de San Matías, concretamente los padrones, las fechas de los mismos son sensiblemente posteriores como para averiguar datos de la vida de Hernando Ortiz. Con respecto a los libros sacramentales, ocurre lo mismo.

${ }^{8}$ La profesora Pilar Bertos, quien ha investigado en profundidad esta temática, reconoce que debido al incendio del archivo en 1981 mencionado anteriormente, no llegó a consultar dichos fondos. P. Bertos Herrera, Los escultores..., op. cit., pp. 14-15. Posteriormente, el archivo se reabrió, pero ya no se ha trabajado en esa cuestión.
9 AHDGr., Legajo 331-F, pieza 2, Contaduría Mayor, pliego de Albolote, año 1602, s/f. "Yglessia de Albolote. Custodia de platta con su viril. Platero Luis de Veas.

En 18 de mayo de 1602 se mando hazer para el serviçio desta yglesia de Albolote una custodia de platta para tener el sagrario y llevar el santísimo sacramento a los enfermos con un pie $y$ ansi mismo un viril de platta para encajar en la dicha custodia y llevar en proçesion el santísimo sacramento la qual dicha custodia a de pessar ocho marcos poco mas a menos y se le a de dar de hechura a tres reales cada marco y la a de dar acavada dentro de un mes desde el dia de la fecha. Encargosse a Hernando Ortiz platero vezino de granada.

\section{Para en quenta.}

En 18 de mayo de 1602 el licenciado Andres Lopez beneficiado de Albolote mayordomo de la yglesia del dicho lugar se libraron a Hernando Ortiz platero quatroçientos reales a quenta de la custodia de platta y dichos quatroçientos reales son los que avia cobrado el dicho licenciado Andres Lopez de Doña Ana Xarava de corridos de un çenso atrasados y el dicho Hernando Ortiz reçivio la libranza y firmo. Hernando Ortiz [rúbrica].

Averiguaçion de quenta de la custodia.

En veinte $y$ uno de henero de 1603 se averiguo quenta con Hernando Ortiz platero de una custodia de plata dorada que hiço para el serviçio de la yglesia de Albolote y como se contiene en la certificaçion del contraste dentro de su pliego pesso la dicha custodia onçe marcos y quatro onças y media que valoro en seteçientos y quarentta $y$ nueve reales.

Yttem dela hechura de los dichos onçe marcos y medio a tres ducados cada marco montan treçientos y setentta y nueve reales.

Ytten el licenciado Andres Lopez beneficiado trato de dorar la dicha custodia toda y concertó dicho dorado della y el trabajo de dorarla en treçientos reales.

= Monto el dorado de la dicha custodia de platta y hechura della mill y quatroçientos y veinte $y$ ocho reales.
En beynte días del mes de febrero de seiscientos y tres años se peso en el contraste de granada una custodia de plata toda dorada con su viril y dos campanillas que peso onçe marcos y quatro onças y media y por la berdad lo firme de mi nonbre. Diego Negrete de Miruelo.

Y costaron los bidrios ocho reales.

En beynte y un días del mes de febrero de mil y seisçientos y tres reçevi la custodia de plata dorada contenida en este pliego para el servicio de la yglesia de albolote. Y lo firme. Licenciado Andres Lopez [rúbrica]".

${ }^{10} \mathrm{P}$. Bertos Herrera, El tema de la Eucaristía... (vol. II), op. cit., pp. 538539.

${ }^{11}$ AHDGr., Legajo 331-F, pieza 3, Contaduría Mayor, pliego de San Pedro y San Pablo, año 1603, s/f. "En 19 de março de 1603 años en Fernando de Quiñones therorero de las yglesias se libraron a Hernando Ortiz platero quinientos reales con que se le acabo de pagar una custodia de plata sobredorada con su beril grande que peso doçe marcos y toda dorada, concertola el Beneficiado Montalbo beneficiado de la yglesia de San Pedro, concertola a quatro ducados cada marco, y el oro en treinta ducados, que vino a montar la plata y hechura y oro mil y seisçientos y treinta y ocho reales, para en quenta de los quales mando su señoria librar los dichos quinientos reales y los mil y çiento y treinta $y$ ocho reales restantes los dio el dicho liçenciado Montalbo de limosna para la dicha custodia entre los reales de la dicha parroquia y el dicho Benefiçiado Montalbo reçivio la dicha custodia y se obligo a ponerlla con los demás bienes de la yglesia y lo firmo. Licenciado Cristobal de Montalbo [rúbrica]".

${ }^{12} \mathrm{M}$. Capel Margarito, Orfebrería religiosa de granada..., op. cit., p. 62.

${ }^{13} \mathrm{P}$. Bertos Herrera, El tema de la Eucaristía... (vol. II), op. cit., pp. 539540.

${ }^{14}$ AHDGr., Legajo 333-F, pieza 2, Contaduría Mayor, pliego de Quéntar, año 1608, s/f. "En 20 de mayo de 1608 en don Gaspar de Pernía mayordomo susodicho se libraron a Hernando Ortiz platero doçientos y treçe reales que 
monto una custodia de plata con su pie que hizo para la yglessia de quentar que pesso ciento y cinquenta $y$ tres reales $y$ sesenta reales de echura y rescibio la la librança y lo firmo. Hernando Ortiz [rúbrica].

Nota marginal: Custodia de plata. Reçebi esta custodia de plata para la yglesia de quentar [rúbrica]".

"En 19 de mayo de 1608 años se peso en el contraste de granada una custodia de plata para los enfermos $y$ peso dos marcos $y$ dos onças $y$ seis ochavas y por la berdad lo firme. Lorenzo de Castro [rúbrica]".

${ }^{15} \mathrm{P}$. Bertos Herrera, El tema de la Eucaristía... (vol. II), op. cit., pp. 530531.

${ }^{16}$ AHDGr., Legajo 333-F, pieza 2, Contaduría Mayor, pliego de Íllora, año 1608, s/f. "Yglessia de Yllora. Custodia de plata dorada. Platero Hernando Ortiz.

En Granada a 15 de septiembre de 1608 su señoría el arçobispo mi señor mando hazer una custodia de plata para el serviçio de la yglessia de la villa de Yllora que pese doze marcos poco más o menos con su pie alto y viril y las quatro canpanillas toda dorada encargose a Hernando Ortiz platero y se le a de dar por cada marco tres ducados de hechura y mas el oro y dorado de por si. A la de dar acavada para fin de mayo deste año de 1609.

Limosna. En seis de septiembre de 1609 dicho Hernando Ortiz platero a quien se encargo dicha custodia de plata rreçivio quarenta ducados por manos del doctor Çatorre Lunel beneficiado

Reçibo de veril viejo. Este dia se entrego a Hernando Ortiz platero un veril viejo dorado de la dicha iglesia de Yllora que pesso un marco y tres onças y dos ochavas la qual se vendio ael maestro Minarro por su pesso y mas tres ducados de la hechura que todo monto $[. .$.$] y veinte y quatro reales. Fir-$ mado Hernando Ortiz.

A cumplimiento. En 29 de mayo de 1609 el beneficiado dela yglessia mayor dela villa de Yllora se libraron a Hernando Ortiz platero noveçientos y setenta y dos rreales con que se le acavan de pagar mil y seisçientos $y$ treinta e ocho rreales que monta la plata $y$ hechura y oro de una custodia grande dorada con un pie y viril y en el cuatro campanillas y un rrelicario de plata dorado para llevar el santísimo sacramento a los enfermos de los cortijos como se contiene por menor dentro deste pliego. Y recibió la libranza y lo firmo. Hernando Ortiz [rúbrica].

En Granada a [...] de junio de mil y seiscientos nuebe años recebi la custodia grande de plata dorada contenida en este pliego para el serviçio de la santa yglessia de la villa de yllora que pesso doce marcos y tres ochabas y assimismo recebi un relicario de plata dorado para llebar el santísimo sacramento a los enfermos de los cortixos que peso treinta y siete reales y lo firme. Luis Çatorre Lunel [rúbrica].

Con el desseo que la persona debota tiene que se haga la custodia de que a vuestra merced di noticia me entrego aier los quarenta ducados que a vuestra merced dixe daba de su debocion que queden en mi poder mientras vuestra merced ordena que los embie que sera esto principio para que se haga una linda pieza sobre el birel que aca ay que lo embiare con el dinero de la debocion desta persona inboca el auxilio de vuestra merced para que luego se ponga por obra pues ay en esta iglessia tanta necesidad $y$ en general esta falta de plata y teniendo a nuestra merced por señor a de estar muy abastecida lo que a menester. Yo quedo con salud y a servicio de vuestra merced. Yllora y agosto 25 1608. El beneficiado Luis Çatorre Lunel.

Pesso de la custodia nueva de platta dorada.

En veinte y quatro días del mes de mayo de 1609 anos se peso en el contraste de Granada una custodia dorada de plata con quatro campanillas y su luneta que peso doce marcos $y$ tres ochavas y por la verdad lo firme. Melchor de Castro [firma y rúbrica].

Mas se peso en este mesmo dia un relicario de enfermos todo dorado por de dentro y fuera $y$ peso treinta y siete reales y por la verdad lo firme. Melchor de Castro [firma y rúbrica].

De los cristales doce reales.

Pesso la custodia doze marcos tres ochavas que valen 783 reales de vellón.
De la hechura a tres ducados cada marco

De los vitrales de viril doze reales.

Del oro con que va dorada la custodia del trabajo de doralla veinte $y$ quatro reales.

Pesso un relicario de platta para llevar el santísimo sacramento a los enfermos de los cortixos treinta y siete reales vellón.

De la hechura y oro del dicho rrelicario.

Pesso del viril viejo.

En Granada al 8 de setiembre de 1608 anos se pesa en el contraste de Granada un belil de plata sobre dorado viejo con su luneta y un cristo y todo peso un marco $y$ tres onças $y$ dos ochavas y por la verdad lo firme. Lorenzo de Castro [firma y rúbrica].

Muncha merced recebi con la de vuestra merced tan llena de las indulgencias y bendiciones de su señoria que a todos tanto a alegrado y en particular a la persona que ofrece la limosna que quisiera dar un millón según su buen desseo aunque vuestra merced enbia a mandar se den los quarenta ducados al platero me parecio ponellos en manos de vuestra merced para que salgan aumentados y multiplicados y assi será vuestra merced servido de mandallos remitir y encargalla haga una muy linda obra y en ella se manifieste en el pueblo que esta yglessia tiene a vuestra merced por señor y los que en ella están por amparo y defensa Dios guarde a nuestra merced largos años. Yllora y setiembre 8 1608. El beneficiado Luis Çatorre Lunel [firma y rúbrica]."

${ }^{17} \mathrm{P}$. Bertos Herrera, El tema de la Eucaristía... (vol. II), op. cit., p. 531.

${ }^{18} \mathrm{P}$. Bertos Herrera, El tema de la Eucaristía... (vol. II), op. cit., p. 528.

${ }^{19}$ AHDGr., Legajo 333-F, pieza 3, Contaduría Mayor, pliego de Güevéjar, año 1608, s/f. "Iglesia de guevejar. Custodia de plata. Hernando Ortiz.

Tiene reçividos Hernando Ortiz para dicha custodia quarenta ducados que le entregaron los herederos del licenciado Montenegro benefiçiado que fue de guevejar que los mando por testamento para una custodia.

En veyntiuno días del mes de mayo de mil y seysçientos y nueve años 
resçevi yo el doctor Fernando de Rivera benefiçiado del lugar de guebejar una custodia de plata con sus viriles y en el dos campanillas y su pie alto que peso ocho marcos y dos onças y seys ochavas para el serviçio de la yglesia del dicho lugar de guebejar y lo firme. El doctor Fernando de Rivera [rúbrica].

En 2 de junio de 1609 en don Fernando de Quiñones thesorero general de las yglesias deste arçobispado de granada se libraron a Hernando Ortiz platero treçientos y setenta reales con que se le acaban de pagar la plata y hechura de una custodia de pie que hizo para el serviçio de la yglesia de guebejar como se contiene dentro deste pliego y reçivio la librança y lo firmo. Hernando Ortiz [rúbrica]".

"En beinte y uno de mayo de 1609 años se peso en el contraste de granada una custodia de plata con dos campanillas y peso ocho marcos y dos onças y seis ochabas y por la berdad lo firme. Melchor de Castro [rúbrica].

Costaron los bidrios quatro reales.

Pesso 142 reales.

Vedrieras 4 reales.

Hechura a 3 reales 264 reales. 410 reales.

Pago el licenciado Montenegro y sus herederos que los mando de limosna quarenta ducados 440 reales.

Restanse en quenta 370 reales".

"En 5 de febrero de 1609 el arçobispo mi señor mando se den de las yglessias veinte ducados para dicha custodia.

El doctor Fernando de Ribera benefiçiado del lugar de guevejar del partido de cogollos digo que el licenciado Montenegro benefiçiado del dicho lugar y vicario de la ciudad de loja mando por su testamento se diesen de su haçienda quarenta ducados a la yglesia del dicho lugar de guebejar, para que se hiçiese una custodia para el santísimo sacramento los quales están ya cobrados $y$ en poder de Hernando Ortiz platero para poner en execuçion lo que mando el dicho vicario y atento que con los dichos quarenta ducados no se puede haçer custodia y solamente abra en ellos para la plata suplico a vuestra señoría ilustrisima se sirva que las yglesias den la hechura de la dicha custodia.
Digo yo Hernando Ortiz platero que están en mi poder quarenta ducados que mando el doctor Montenegro benefiçiado que fue de guevexar para una custodia para aquella yglesia de que hiçe escritura en favor de sus herederos obligome a haçer una custodia y pesa siete marcos la qual dare acabada dentro de dos meses desde oy dia de la fecha, fecha en granada en seis de febrero de mil y seisçientos y nuebe años. Hernando Ortiz. El doctor Ribera [rúbricas]".

${ }^{20} \mathrm{P}$. Bertos Herrera, El tema de la Eucaristía... (vol. II), op. cit., p. 535.

${ }^{21}$ AHDGr., Legajo 334-F, pieza 1, Contaduría Mayor, pliego de Monachil, año 1610, s/f. "En 9 de agosto de 1610 años en Miguel de Vicuña mayordomo se libraron a Hernando Ortiz platero çiento y ochenta y nueve reales por una custodia de plata que hizo para llevar el santísimo sacramento a los enfermos del lugar de monachil y para que este en la yglesia con deçencia los çinquenta reales de la hechura y lo demás de plata como se contiene dentro deste pliego y reçivio la librança y lo firmo. Hernando Ortiz [rúbrica].

Este dicho dia se entrego la custodia arriba contenida al maestro Paniza benefiçiado de la yglesia de guetor y lo firmo. El maestro Francisco de Paniza Ladrón [rúbrica]".

"En siete días del mes de agosto de seisçientos y diez años se pesso en el contraste de granada una custodia de plata con su tapador y cruz y pesso dos marcos y una onza y ochava y media que montan çiento y treinta y nueve reales y medio y por la verdad lo firme. Cristobal de Ribas Perez [rúbrica]

$\begin{array}{ll}\text { Hechura } & 50 \text { reales. } \\ \text { Plata } & 139 \text { reales } \\ & 189 \text { reales". }\end{array}$

${ }^{22} \mathrm{P}$. Bertos Herrera, El tema de la Eucaristía... (vol. II), op. cit., p. 539. Ese pormenor de pensar que la custodia es anterior ya lo asevera la propia autora.

${ }^{23}$ AHDGr., Legajo 337-F, pieza 1, Contaduría Mayor, pliego de Padul, año 1616, s/f. "En granada a quinçe de julio de mil y seysçientos y diez y seys años se pesó en el contraste desta çiudad una custodia de plata blanca con su caja para los enfermos y su viril para descubrir el santísimo sacramento y pesó seys marcos, seys onzas y tres ochavas y por la verdad lo firmé. Juan Tellez [rúbrica]

De los viriles seys reales

Plata seys marcos seis onzas $y$ tres ochavas 441 reales.

Hechura destos marcos a tres $d u$ cados el marco 222 reales.

Total monta 663 reales".

"En 28 de julio de 1616 años se aberiguo quenta con Hernando Ortiz platero vezino desta ciudad de lo que montó una custodia de plata que hiço para llevar el santísimo sacramento a los enfermos y un biril ençima para que esté manifiesto el santísimo sacramento en algunas festividades y como se contiene en la ffe del contraste questa dentro deste pliego peso la dicha custodia seis marcos y seis onzas $y$ tres ochavas que haçen quatrocientos y quarenta $y$ un reales-. De la hechura de la dicha custodia a tres ducados cada marco duçientos $y$ veinte $y$ dos reales-. Que monta la dicha custodia seiscientos $y$ sesenta y tres reales.

Los quales se libraron en Baltasar de Calbache a quenta de los maravedis que cobra de las yglesias que resto deviendo el señor don fray Pedro González de Mendoza lo qual se libro en libranza de 801 reales en este dicho dia.

En 30 de julio de mil y seiscientos y diez y seis años recibi la custodia de plata contenida en esta partida y lo firmé. Recibi esta libranza a Hernando Ortiz y lo firmó [rúbrica]. Dr. Basilio Altamirano [rúbrica]".

${ }^{24}$ AHDGr., Legajo 336-F, pieza 2, Contaduría Mayor, pliego de Huétor Vega, año 1615, s/f. "En 22 de marzo de 1615 años en el mayordomo Francisco Paniza Ladron beneficiado de guetor y mayordomo de los habizes de las iglesias de guetor, cajar y monachil se libraron a Hernando Ortiz platero veçino desta çiudad de granada treçientos y treinta y ocho reales que ubo de aver por una custodia de plata que hiço para el serviçio de la yglesia de guetor y de la hechura esta custodia es para tener el santísimo sacramento en la yglesia y llevarlo a los enfermos como se contiene en la fee del contraste que está dentro deste pliego-

Reçebi esta custodia de plata para el serbizio de la yglesia de guetor. 
El maestro Francisco Paniza Ladron [rúbrica]".

"En onze días del mes de marzo de mil y seisçientos y quinze años se pesso en el contraste de granada un relicario de plata y pesso duzientos y trenta y dos reales y lo firmé que hazen tres marcos y medio y quatro ochavas $y$ media. Jerónimo de Nicuesa [rúbrica].

Del oro y hazogue 20 reales.

Pesa la custodia de plata 232 reales.

Del oro con que va dorada la copa 10 reales.

De la hechura tres marcos y medio que pessa a dos ducados y medio 26 reales 338 reales.

Que se libraron al Maestro Paniza mayordomo de los havices de monachil en 20 de março de 1615 años".
${ }^{25}$ AHDGr., Legajo 332-F, pieza 1, Contaduría Mayor, pliego de Moclín, año 1604, s/f.

${ }^{26}$ AHDGr., Legajo 333-F, pieza 3 , Contaduría Mayor, pliego de Güevéjar, año 1609, s/f.

${ }^{27}$ AHDGr., Legajo 335-F, pieza 3 , Contaduría Mayor, pliego de Santa Escolástica, año 1612, s/f.

${ }^{28}$ AHDGr., Legajo 335-F, pieza 3, Contaduría Mayor, pliego de Guadahortuna, año 1612, s/f.

${ }^{29}$ AHDGr., Legajo 336-F, pieza 1, Contaduría Mayor, pliego de Churriana de la Vega, año 1614, s/f.

${ }^{30}$ AHDGr., Legajo 336-F, pieza 2, Contaduría Mayor, pliego de Albuñuelas, año 1615 , s/f.
${ }^{31}$ AHDGr., Legajo 337-F, pieza 1, Contaduría Mayor, pliego de Dalías, año 1616, s/f.

${ }^{32}$ AHDGr., Legajo 337-F, pieza 1, Contaduría Mayor, pliego de Cogollos, año $1616, \mathrm{~s} / \mathrm{f}$.

${ }^{33}$ AHDGr., Legajo 337-F, pieza 1, Contaduría Mayor, pliego de Iznalloz, año 1616 , s/f.

${ }^{34}$ AHDGr., Legajo 331-F, pieza 2, Contaduría Mayor, pliego de Huétor Santillán, año 1602, s/f.

${ }^{35}$ AHDGr., Legajo 334-F, pieza 1, Contaduría Mayor, pliego de Virgen de las Angustias, año 1610, s/f.

${ }^{36}$ AHDGr., Legajo 333-F, pieza 2, Contaduría Mayor, pliego de Gabias, año 1608 , s/f. 


\section{REFERENCIAS}

Bertos Herrera, Pilar. 1985. El tema de la Eucaristía en el arte de Granada y su provincia. Granada: Universidad de Granada.

Bertos Herrera, Pilar. 1991. Los escultores de la plata y el oro. Granada: Universidad de Granada.
Capel Margarito, Manuel. 1986. Orfebrería religiosa de granada. Granada: Diputación de Granada.

Sanz Serrano, María Jesús. 1976. La orfebrería sevillana del Barroco. 2 vols. Sevilla: Diputación de Sevilla. 